\title{
THỰC TRANG SÂU RĂNG SỚM Ở TRẺ TỰ KỶ ĐƯợC ĐIỀU TRI TẠI BỆNH VIỆN NHI TRUNG ƯƠNG NĂM 2020-2021
}

\section{TÓM TẮT}

Mục đích: Nghiên cứu mô tả thực trang sâu răng sớm ở trẻ tự kỷ được điều trị tại bệnh viện Nhi Trung ương năm $2020-2021$. Đối tượng và phương pháp: Nghiên cứu cắt ngang mô tả trên 107 trẻ từ 2 tới 5 tuối được bác sĩ khoa Tâm thần Bệnh viện Nhi Trung ương chẩn đoán xác đinh là tư kỷ và hợp tác được khi thăm khám nha khoa.Tổn thương sâu răng được khám bằng mắt thường theo hêe thống tiêu chí phát hiện và đánh giá sâu răng sớm của WHO. Kết quả: 107 trẻ có $81,3 \%$ nam, 18, 7\% nữ với tỷ lệ sâu răng sớm là $52,34 \% ; 39,25 \%$ trẻ tự kỷ nhẹ - trung bình, 60,75\% trẻ tư kỷ năng;Chỉ số sâu mất trám (dmft) là 2,97. Kết luận: Tỷ lệ sâu răng sớm của trẻ tư kỷ ở mức trung bình. Cần có thêm nhiều nghiên cứu và các phương pháp tiếp cận mới để cải thiện tình trạng răng miệng cho trẻ tự kỷ.

Tư khóa: trẻ tự kỷ; sẩu răng sớm;Chỉ số sâu mất trám răng sữa (dmft).

\section{SUMMARY \\ THE STATE OF EARLY CARIES IN CHILDREN WITH AUTISM TREATMENTED AT THE NATIONAL CHILDREN'S HOSPITAL IN 2020 -2021 \\ Introdution: The study aimed to descrip the state} of early caries in children with autism treatmented at the National Children's Hospital in $2020-2021$. Subjects and methods: Cross-sectional descriptivestudyon 107 children from 2 to 5 years old who were diagnosed with autism by a psychiatrist at National Children's Hospital and cooperated in dental examination. Caries lesionswere examined visually to the WHO system of early caries development and assessment criteria. Results: 107 children were $81.3 \%$ male, $18.7 \%$ female with an early result deviation rate of $52.34 \%$. $39.25 \%$ children with mild autism - moderate, $60.75 \%$ children with severe autism. The Decayed, Missing, and Filled Teeth (dmft) index is 2.97. Conclusion: The early caries rate of children with autism is average. More research and new approaches are needed to improve the oral health of children with autism.

Keywords: children with autism; early caries; The Decayed, Missing, and Filled Teeth (dmft) index.

\section{I. ĐẶT VẤN ĐỀ}

Sâu răng là một bệnh phổ biến ở trẻ em, nếu

\author{
${ }^{1}$ Bênh viện Nhi Trung ương. \\ 2 Viên đào tạo Răng Hàm Mặt - Đai học Y Hà Nội \\ Chịu trách nhiệm chính: Nguyễn Mai Phương \\ Email: maiphuong8988@gmail.com \\ Ngày nhận bài: 17.5.2021 \\ Ngày phản biên khoa hoc: 9.7.2021 \\ Ngày duyệt bài: 19.7.2021
}

\section{Nguyễn Mai Phương1, Vũ Mạnh Tuấn ${ }^{2}$}

không được điều trị có thể dẫn đên bệnh lý tủy tủy răng, bệnh lý cuống răng và nhiễm trùng cấp tính vùng hàm mặt hay toàn thân, ảnh hưởng đến sức khỏe của trẻ.

Tự kỷ là sự rối loạn phát triển lan tỏa do bất thường của não bộ, xuất hiện sớm trong những năm đâu đời của trẻ em (thường là trước 3 tuổi) và diễn biến kéo dài, ảnh hưởng không nhỏ tới cuộc sống của trẻ và gia đình trẻ. Trong vài thâp kỷ gần đây các nghiên cứu cho thấy tỷ lệ mắc tự kỷ tăng nhanh chóng. Tỷ lệ mắc tự kỷ theo Baird và cộng sự (1999) là $3 \% 0^{3}$; theo số liệu của Trung tâm Kiểm soát và Phòng bệnh năm 2009 tại Mỹ là $1 / 110$ trẻ sơ sinh sống $\left(6,6 \%\right.$ o ${ }^{4}$. Nghiên cứu của Kim và cộng sự tại Hàn Quốc cho tỷ lệ hiện mắc tự kỷ là $1 / 38$ trẻ $(2,6 \%)^{4}$.

Hiện nay, phương pháp chữa khỏi hoàn toàn tự kỷ chưa được tìm ra nhưng đã có nhiêu cách tiếp cận để điều trị cải thiện tình trạng rối loạn ở trẻ tự kỷ. Can thiệp sớm trong 5 năm đầu có thể làm tăng chất lượng cuộc sống cho trẻ và gia đình trẻ, giúp trẻ tăng khả năng hòa nhập với xã hội.Trước đây đã có một số nghiên cứu ở Việt Nam về thực trang sâu răng của trẻ tự kỷ. Tuy nhiên các nghiên cứu thường giới hạn tại một số trung tâm chăm sóc trẻ khuyết tật hay một trường mầm non cho trẻ đặc biệt, ít đề cập tới các yếu tố nguy cơ gây bệnh sâu răng, đặc biệt là sâu răng sớm của trẻ tự kỷ. Do vậy chúng tồi tiến hành đề tài nghiên cứu với mục tiêu: Mô tả thực trạng sâu răng sớm ở trẻ tự kỷ được điều trị tại bệnh viện Nhi Trung ương năm 2020 -2021.

\section{II. ĐỐI TƯỢNG VÀ PHƯƠNG PHÁP NGHIÊN CỨU}

1. Thời gian và địa điểm nghiên cứu:từ 1/9/2020 đến 30/07/2021, Khoa Tâm thần của Bệnh viện Nhi Trung ương.

\section{2. Đối tượng nghiên cứu}

- Tiêu chuẩn lựa chọn: Bệnh nhân được bác sĩ khoa Tâm thần Bệnh viện Nhi Trung ưởng chẩn đoán xác đinh là tư kỷ và hợp tác được khi thăm khám nha khoa, độ tuổi từ $2-5$ tuổi, được sự đồng ý của phụ huynh hoặc người giám hộ.

- Tiêu chuẩn loại trừ: Trẻ tự kỷ 2 - 5 tuổi nhưng không hợp tác được khi thăm khám. Không có sư đồng ý của phụ huynh.

3. Thiết kế nghiên cứu, cỡ mẫu, cách chọn mấu

Thiết kế nghiên cứu: nghiên cứu mô tả cắt ngang 

thức

Cỡ mẫu nghiên cứu: được tính theo công

$$
Z_{\mathrm{n}=\frac{\alpha}{2}}^{2} \frac{p(1-p)}{d^{2}}
$$

$\mathrm{n}$ : Cỡ mẫu tối thiếu của đối tượng trẻ em mắc bệnh tự kỷ

a: Mức ý nghĩa thống kê; $a=0,05$ thì hệ số giới hạn tin cậy $Z_{1}$ - a/2 $=1,96$.

$\mathrm{p}$ : Tỷ lệ trẻ tự kỷ bị mắc bệnh sâu răng sớm. Ước tính $\mathrm{p}=0,8$

d: Độ chính xác mong muốn 0.08

Từ công thức trên tính được cỡ mẫu cần nghiên cứu $n$ là 97 cộng thêm $10 \%$ (107 bệnh nhi trong nghiên cứu).

Cách chọn mẫu: Chọn mẫu có chủ đích. Chọn trẻ tự kỷ đến khám và được điều trị tại khoa Tâm thần, Bệnh viện Nhi Trung ương đủ tiêu chuẩn lựa chọn cho đến khi đủ 107 trẻ.

4. Các biến số trong nghiên cứu: thông tin về tuổi, giới, điểm CARS, sâu răng, mất răng, trám răng, chỉ số dmftđược ghi nhận theo mẫu bệnh án.

\section{KẾT QUẢ NGHIÊN CỨU}

1. Đặc điểm đối tượng nghiên cứu phân bố bệnh nhi the o tuổi- giới

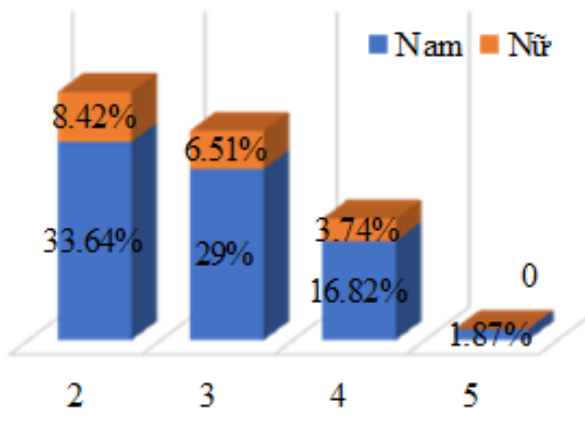

Biểu đồ 1. Phân bố đôi tượng bệnh nhi theo tuổi và giới

Nhận xét: Trong 107 trẻ tự kỷ: bệnh nhi 2 tuổi chiếm 42,06\% (45 trẻ: 36 nam/9 nữ); 3 tuổi chiếm 35,51\% (38 bệnh nhi: 31 nam/7 nữ); 4 tuổi chiếm 20.56\% (22 bệnh nhi: 18 nam/4 nữ), 2 bệnh nhi 5 tuổi chiếm $1.87 \%$ (2 nam/0 nữ).

Bảng 1. Mức độ tự kỷ của trẻ trong nghiên cứu

\begin{tabular}{|c|c|c|c|}
\hline Mức độ & $\begin{array}{c}\text { Nhe - } \\
\text { Trung } \\
\text { bình }\end{array}$ & Nặng & p \\
\hline $2-3$ tuổi & $\begin{array}{c}29 \\
27,10 \%\end{array}$ & \begin{tabular}{c}
$50,47 \%$ \\
\multirow{2}{*}{0}
\end{tabular} & \multirow{2}{*}{$089 \%$} \\
\hline $4-5$ tuối & 13 & 11 & \\
\hline
\end{tabular}

\begin{tabular}{|c|c|c|c|}
\hline & $12,15 \%$ & $10,28 \%$ & \multirow{2}{*}{ Tổng } \\
\hline \multirow{2}{*}{ Tôn } & $32,25 \%$ & $60,75 \%$ & \\
\hline
\end{tabular}

*test $X^{2}$

Nhận xét: Trong 107 trẻ tự kỷ được điều trị tại bệnh viện Nhi Trung ương, tỉ lệ trẻ mắc tự kỷ mức độ nặng (65 trẻ: chiếm 60,75\%) cao hơn trẻ tự kỷ mức độ nhẹ và trung bình (42 trẻ: chiếm 39,25\%). Trong đó, trẻ ở nhóm 2-3 tuổi mắc tự kỷ mức độ nặng chiếm tî lệ cao nhất (50,47\%). Sự khác biệt không có ý nghĩa thống kê giữa mức độ tự kỉ và nhóm tuổi của trẻ với $p=0,089>0,05$.

\section{Tình trạng sâu răng sớm}

Bảng 2. Tỷ lệ sâu răng sớm theo tuổi

\begin{tabular}{|c|c|c|c|c|}
\hline $\begin{array}{c}\text { Sâu } \\
\text { răng } \\
\text { sớm }\end{array}$ & $\begin{array}{c}\text { Tuối } \\
\text { tuổi 2- } \\
\mathbf{3}\end{array}$ & $\begin{array}{c}\text { Nhóm } \\
\text { tuổi 4- } \\
\mathbf{5}\end{array}$ & Tổng & $\mathbf{p}$ \\
\hline Có Sâu & 41 & 15 & 56 & \\
\hline & $49,40 \%$ & $\begin{array}{c}62,50 \\
\%\end{array}$ & $52,34 \%$ & \\
\hline $\begin{array}{c}\text { Không } \\
\text { sâu }\end{array}$ & 42 & 9 & 51 & $\begin{array}{c}0,2 \\
58^{*}\end{array}$ \\
\hline & $50,60 \%$ & $\begin{array}{c}37,50 \\
\%\end{array}$ & $47,66 \%$ & \\
\hline Tống & 83 & 24 & 107 & \\
\hline & $100 \%$ & $100 \%$ & $100 \%$ & \\
\hline
\end{tabular}

*test $X^{2}$

Nhận xét: Tỉ lệ sâu răng sớm của nhóm tuổi từ 4 đến 5 tuổi $(62,50 \%)$ cao hơn so với nhóm tuổi từ 2 đến 3 tuối $(49,40 \%)$. Sự khác biệt không có ý nghĩa thống kê với

$$
p=0,258>0,05 \text {. }
$$

Bảng 3. Tỉ lệ sâu răng sớm theo mức độ

\begin{tabular}{|c|c|c|c|c|}
\hline $\begin{array}{l}\text { Mức độ } \\
\text { Sâu răng } \\
\text { sớm }\end{array}$ & $\begin{array}{l}\text { Nhe - } \\
\text { Trung } \\
\text { bình }\end{array}$ & Nặng & Tổng & $\mathbf{p}$ \\
\hline Có sâu & $\begin{array}{c}21 \\
50 \%\end{array}$ & $\begin{array}{c}35 \\
53,85 \%\end{array}$ & $\begin{array}{c}56 \\
52,34 \%\end{array}$ & \multirow{3}{*}{$\begin{array}{l}0,1 \\
78^{*}\end{array}$} \\
\hline Không sâu & $\begin{array}{c}21 \\
50 \%\end{array}$ & $\begin{array}{c}30 \\
46,15 \%\end{array}$ & $\begin{array}{c}51 \\
47,66 \% \\
\end{array}$ & \\
\hline Tổng & $\begin{array}{c}42 \\
100 \%\end{array}$ & $\begin{array}{c}65 \\
100 \% \\
\end{array}$ & $\begin{array}{c}107 \\
100 \%\end{array}$ & \\
\hline
\end{tabular}
tư $k \dot{y}$

*test $\mathrm{X}^{2}$

Nhận xét: Tỉ lệ sâu răng sớm của nhóm tự kỷ nặng $(53,85 \%)$ cao hơn tỉ lệ sâu răng sớm của nhóm tự kỷ nhẹ và trung bình $(50 \%)$. Sự khác biệt khổng có ý nghĩa thông kê với $p=0,178>$ 0,05 .

3. Phân bố chỉ số sâu mất trám theo nhóm tuổi 


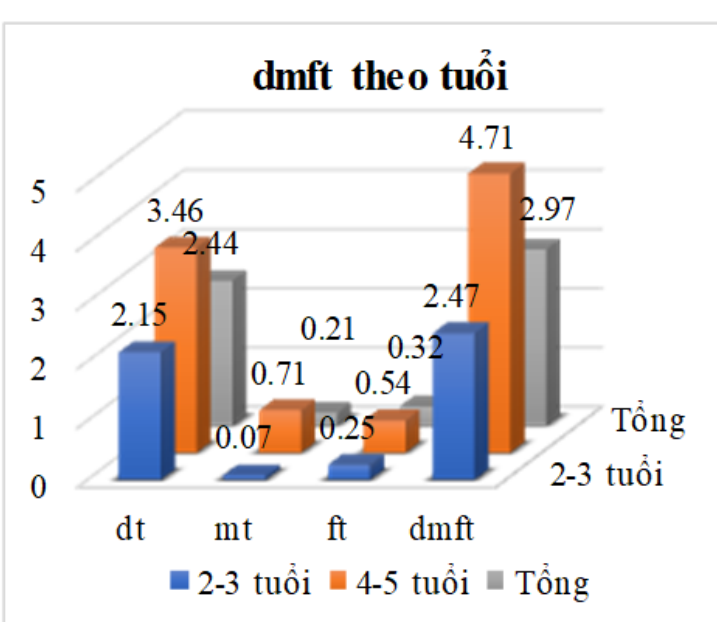

Biêu đồ 2. Chi số sâu mất trám theo nhóm tuổi

Nhận xét: Chỉ số sâu mất trám răng sữa ở nhóm 4-5 tuổi $(4,71)$ cao hơn chỉ số sâu mất trám răng sữa ở nhóm 2-3 tuổi $(2,47)$.

\section{BÀN LUẬN}

Trong tổng số 107 bệnh nhi tham gia nghiên cứu, có 87 bệnh nhi nam (chiếm $81,31 \%$ ) và có 20 bệnh nhi nữ (chiếm 18,69\%). Cho thấy tỷ lệ phân bố không đồng đều ở 2 giới, bệnh nhi nam chiếm đa số. Kết quả này tương tự như nghiên cứu của Đố Hoàng Việt ${ }^{1}$ có tỉ lệ trẻ nam chiếm $83,91 \%$ và tỉ lệ trẻ nữ chiếm $16,09 \%$. Tỷ lệ này phù hợp với đặc điểm dịch tễ của trẻ em mắc tự kỷ².

Phân tích Bảng 1 ta thây tỉ lệ trẻ mắc tự kỷ mức độ nặng (65 trẻ: chiếm $60,75 \%$ ) cao hơn trẻ tự kỷ mức độ nhẹ và trung bình (42 trẻ: chiếm 39,25\%). Trong đó, trẻ ở nhóm 2-3 tuổi mắc tự kỷ mức độ nặng chiếm tỉ lệ cao nhất $(50,47 \%)$. Bệnh viện Nhi Trung ương là một bệnh viện tuyến Trung ương. Trẻ được khám, chẩn đoán bệnh và chẩn đoán mức độ tự kỷ. Đa số trẻ được chẩn đoán tự kỷ mức độ nặng sẽ được điều trị theo từng đợt tại bệnh viện $\mathrm{Nhi}$ Trung ương. Tự kỷ được chẩn đoán sớm ở trẻ từ 2 tuổi và điều quan trọng là điều trị hiệu quả nhất khi trẻ ở giai đoạn sớm.Vì vậy tỉ lể trẻ 2 tuổi là nhiều nhất (chiếm 42,06\%), sau đó tỉ lệ giảm dần theo lứa tuổi. Tỉ lệ trẻ tự kỷ mức độ nặng cao hơn tỉ lệ trẻ tự kỷ mức độ nhẹ và trung bình và trẻ tự kỷ mức độ nặng ở nhóm 2-3 tuổi chiếm tỉ lệ cao nhất.

Theo phân loại mức độ sâu răng của tổ chức y tế thế giới (WHO), tỉ lệ sâu răng trong nghiên cứu này thuộc mức trung bình 52,34\% (Bảng2).

Một số nghiên cứu về tình trạng răng miệng ở trẻ khuyết tật trên thế giới và tại Việt Nam đều có tî lệ sâu răng nằm trong mức từ trung bình đến cao như nghiên cứu của Mohamed Abdullah Jaber (Arab, 2011) trên trẻ tự kỷ $(77 \%)^{6}$; nghiên cứu của Shyama cùng cộng sự (2001, Kwait) trên trẻ khuyết tật từ 3-29 tuổi $(86 \%)^{7}$. Sự khác biệt trong nghiên cứu của chúng tôi có thể là do Bệnh viện Nhi Trung ương là tuyến Trung ương và ở tại thủ đô Hà Nội, nơi có mức độ dân trí cao. Đa phần gia đình các trẻ tự kỷ cho con học và điều trị tại Bệnh viện Nhi Trung ương đều quan tâm chăm sóc trẻ toàn diện.

Theo Bảng2 cho thấy tỉ lệ sâu răng sớm của nhóm $4-5$ tuổi $(62,50 \%)$ cao hơn so với nhóm 2 - 3 tuổi (49,40\%). Sự khác biệt không có ý nghĩa thống kê với $p=0,258>0,05$. Điều này có thể giải thích giai đoạn từ 2 - 3 tuổi là giai đoạn hình thành hàm răng sữa, do đó, số lượng răng sữa ở nhóm tuổi này ít hơn so với nhóm $4-6$ tuổi đã hoàn thành toàn bộ hàm răng sữa. Ngoài ra, giai đoạn $4-6$ tuổi có thời gian các răng sữa bị phơi nhiễm với các yếu tố gây bệnh sâu răng lâu hơn nên có nguy cơ cao hơn.

Kết quả nghiên cứu cho thây tỉ lệ sâu răng sớm của nhóm trẻ tự kỷ nặng là $53,85 \%$, cao hơn so nhóm trẻ tự kỷ nhe và trung bình (50\%). Điều này có thể giải thích là các trẻ tự kỷ mức độ nặng có các rối loạn chức năng mức độ nặng. Bởi vậy, cha mẹ trẻ tự kỷ nặng gặp nhiều khó khăn hơn trong việc chăm sóc và vệ sinh răng miệng cho trẻ so với trẻ tự kỷ nhẹ và trung bình. Ngoài ra, việc tiếp cận khám và điều trị răng miệng cho trẻ tự kỷ nặng cũng khó khăn hơn so với trẻ có mức độ tự kỷ nhe và trung bình. Tuy nhiên,sự khác biệt này không có ý nghĩa thống kê với $p=0,178>0,05$ (kiểm định $x^{2}$ ).

Chỉ số sâu mất trám răng sữa chung của nhóm nghiên cứu $(2,97)$ ở mức trung bình.Chỉ số dmft ở nhóm 4-5 tuối $(4,71)$ cao hơn chỉ số dmft ở nhóm 2-3 tuổi $(2,47)$. Chỉ số dmft có xu hướng gia tăng theo tuổi vì thời gian răng sữa phơi nhiễm trong môi trường miệng.

\section{KẾT LUẬN}

Nghiên cứu cho thấy tình trạng sâu răng sớm ở trẻ tự kỷ ở mức trung bình $(52,34 \%)$ và tî lệ sâu răng sớm ở nhóm 4-5 tuổi cao hơn nhóm 2-3 tuổi. Tỉ lệ sâu răng sớm của nhóm trẻ tự kỷ nặng cao hơn nhóm trẻ tự kỷ nhe và trung bình.Do vậy, cần điều trị và dự phòng sâu răng cho các trẻ tự kỷ để giảm sự gia tăng tỉ lệ sâu răng sớm theo tuổi trên trẻ.

Trong những năm vừa qua, xã hội đã có nhiều quan tâm tích cực về trẻ tự kỷ, nhiều trung tâm đặc biệt đã được mở ra để giáo dục kỹ năng sống cho trẻ tự kỳ. Cha mẹ cũng đã quan tâm 
tìm hiểu nhiều hơn về tự kỷ và áp dụng nhiều phương pháp giáo dục, chăm sóc tiên tiến. Can thiệp sớm trong 5 năm đầu có thể làm tăng chất lượng cuộc sống cho trẻ và gia đình trẻ, giúp trẻ tăng khả năng hòa nhập với xã hội. Cần có thêm nhiều nghiên cứu và các phương pháp tiếp cận mới để cải thiện tình trạng răng miệng cho trẻ tự kỷy.

\section{TÀI LIÊU THAM KHẢO}

1. Đố Hoàng Việt (2013). Nhận xét thực trạng sâu răng, viêm lợi của trẻ mắc bệnh tự kỷ tai trường mầm non Newstar năm 2012, Luận án tốt nghiệp đại học, Trường đại học Y Hà Nội.

2. Nguyến Thi Hương Giang, Trân Thu Hà (2008). Nghiên cứu xa thể mắc và một số đặc điểm dich tể hoc của trẻ tư kỷ điêu tri tai Bênh viện Nhi Trung ương giai đoạn 2000- 2007, Y học thực hành, 4, tr 104-107.

3. Baird G., Charman T. et al. (2000). A Screening instrument for autism at 18 months of age: A 6years follow-up study. Journal of the American Academy of Child and Adolescent Psychiatry. 39, pp. $694-702$.

4. Centers for Disease Control and Prevention (2010). Prevalence of the Autism Spectrum Disorders - Autism and Developmental Disabilities Monitoring Network, 2006. Surveillance Summaries. 59(30); pp. 956.

5. Kim Y. S., Leventhal B. et al. (2011) Prevalence of Autism Spectrum Disorder in a total population sample. The American Journal of Psychiatry. 168, pp. $904-912$.

6. Mohamed Abdullah Jaber (2011), Dental caries experience, oral health status and treatment needs of dental patients with autism, Journal of applied pral science, no.3.

7. Shyama M (2001). Dental caries experience of disable children and young adult in Kuwait. Community dental health,18, p. $181-186$.

\section{ĐÁNH GIÁ HIÊU QUẢ ĐIỀU TRI BÊNHH NHÂN LYMPHOMA THỂ NANG VỚI PHÁC ĐỒ CÓ RITUXIMAB SẢU 7 NĂM TẠI KHOA HUYẾT HỌC BÊ̂NH VIÊ̂N CHỢ RẪY}

\section{TÓM TẮT}

Mục tiêu: Đánh giá hiệu quả điều trị bệnh nhân lymphoma thể nang với phác đồ có Rituximab tại khoa Huyết học - Bệnh viện Chợ Rẫy từ tháng 01 năm 2014 đến tháng 7 nằm 2021. Đối tượng và phương pháp nghiên cứu: Nghiên cứu mô tả, tiến cứu và hồi cứu loạt ca nhóm bệnh nhân lymphoma thể nang có CD20 (+) được chẩn đoán và điêu trị theo phác đồ có Rituximab tại Khoa Huyết Học -Bệnh viên Chợ Rẫy từ tháng 01/2014 đến tháng 07/2021. Kết quả: Qua nghiên cứu 54 bệnh nhân lymphoma thể nang, bước đầu chúng tôi ghi nhân được các kết quả như sau: độ tuổi trung bình của bệnh nhân (BN) là 54 tuổi (từ 26 83 tuổi). Tỉ lệ nam/nữ là 1:1,08. Phần lớn bệnh nhân nhập viện ở giai đoạn trễ, (giai đoạn III-IV - 72,2\%). Phẩn nhóm nguy cở theo chỉ số tiên lượng quốc tế FLIPI: nhóm nguy cơ thấp, trung bình, cao theo thứ tự lần lượt là $22,2 \%, 29,6 \%$ và $48,1 \%$. Bênh nhân có triệu chứng $B$ chiếm $59,3 \%$. Bệnh biểu hiện chủ yếu tai hach $(72,2 \%)$, lách $(25,9 \%)$, xâm lấn tủy $(20,4 \%)$, và tại các cơ quan khác: tá tràng, ruột non, ruột già, hốc mắt. Tất cả các bệnh nhân đêu được điều trị với các phác đồ kết hợp Rituximab bao gồm RCHOP $(72,2 \%)$, RB $(20,4 \%)$, RCVP $(3,7 \%)$ và Rituximab đơn

${ }^{1}$ Đại học Y Dược TP. Hồ Chí Minh

${ }^{2}$ Bềnh viên Chơ Rẫy

Chịu trách nhiệm chính: Lê Thị Phương Thảo

Email: dr.phuongthao3012@gmail.com

Ngày nhận bài: 14.5.2021

Ngày phản biên khoa hoc: 8.7.2021

Ngày duyệt bài: 16.7.2021

\section{Lê Thị Phương Thảo ${ }^{1,2}$, Lê Hoàng Oanh²}

trị (3,7\%). Tỉ lệ đáp ứng chung 98,1\% (đáp ứng hoàn toàn - CR là $79,6 \%$, đáp ứng một phần - $\mathrm{PR}$ là $18,5 \%)$. Thời gian sống còn trung bình là 71,5 tháng $\pm 4,3$ tháng. Xác suất sống còn toàn bộ 7 năm là $73,3 \% \pm 8,1 \%$. Thời gian sống còn không bênh tiến triển trung bình là 34,4 tháng (4 tháng - 84 tháng). Xác suất sống còn không bệnh tiến triển 7 năm là $49,1 \% \pm 1,19 \%$. Kết luận: Qua nghiên cứu, chúng tôi ghi nhân điều trị bênh nhân Lymphoma thể nang với phác đồ có Rituximab đat tỉ lệ đáp ứng cao.

Tư khóa: lymphoma thể nang, rituximab

\section{SUMMARY}

EVALUATE THE EFFICACY OF FOLLICULAR LYMPHOMA PATIENTS WITH RITUXIMABCONTAINING REGIMEN AFTER 7 YEARS AT THE DEPARTMENT OF HEMATOLOGY, - CHO RAY HOSPITAL

Objectives: To evaluate the treatment effect of follicular lymphoma patients with rituximab-containing regimen at the Department of Hematology, Cho Ray Hospital from 2014 to 2021. Subjects and methods: Descriptive, prospective, and retrospective study of a series of $\operatorname{CD20}(+)$ follicular lymphoma patients diagnosed and treated according to rituximabcontaining regimens at the Department of Hematology - Chong Hospital from January 2014 to July 2021. Results: Through the study of 54 patients with follicular lymphoma, we initially recorded the following results: the mean age of the patient was 54 years old (from 26 to 83 years old). Male/Female ratio: 1:1.08. The majority of patients hospitalized in the late stage of disease (stage III-IV - 72,2\%). Classification of risk 